\title{
Analysis on the Features of College Students' Online Consumption Behaviors and Its Educational Countermeasures
}

\author{
ZHANG Ji \\ Lecturer, currently works in Ideology and Politics \\ Department of Chengdu Polytechnic \\ Doctor of Southwest Jiaotong University \\ Chengdu, China
}

\author{
YANG Yanhong \\ Lecturer and Master, currently works in Ideology and \\ Politics Department of Jiangxi University of Technology \\ Nanchang, China
}

\begin{abstract}
In the information society, online consumption has been a popular way of consumption among college students. This paper starts from the angle of ideological and political education to analyze the characteristics of college students' online consumption behaviors, and seeks feasible countermeasures of educational practice on this basis to improve their online consumption behaviors. These countermeasures call for joint efforts from families, colleges and government institutions, and serve to improve students' online consumption mode by guiding them with a healthy, dynamic and high campus and network culture.
\end{abstract}

Keywords-college students; online consumption; behavior features; educational countermeasures

As the virtual network extends itself into real life, online consumption platforms are developing and expanding rapidly, and college students have become the major followers of the new-type consumption mode. Marx once pointed out, "Ever since the first day of human existence on Earth, humans have to consume goods, whether the consumption happens before or during the production." Online consumption behavior itself is an economic phenomenon that reflects people's moral values. The 18th CPC National Congress Report emphasized "the necessity of fully implementing the Party's educational guidelines, sticking to serving people and socialist modernization with education, regarding moral composition as a fundamental task of education, and bringing up socialist constructers and successors with all-around development of morality, intelligence, physique and aesthetics." Online consumption behaviors of college students can directly influence the development of their view of consumption and life. Thus, this issue deserves the attention from the whole society.

\section{CHARACTERISTICS OF COLLEGE STUDENTS` ONLINE CONSUMPTION BEHAVIORS}

Abraham Harold Maslow, a US psychologist, proposed the famous theory of hierarchy of needs in his paper, A Theory of Human Motivation, published in 1943. The theory illustrates

This paper is a part of the research findings of the National School Communist Youth League research project (2015LX297), Sichuan Provincia Educational Bureau research project (16SB0349), and Chengdu Polytechnic Youth Fund project (15CZY37) individual needs from the bottom to the top of the hierarchy, and points out that motivation of needs forms the internal strength for individual growth. Therefore, needs at each layer and the satisfaction of these needs decide the level of development of individual personality. According to Maslow's theory of hierarchy of needs, features of college students' online consumption behaviors can be boiled down into the following three points:

\section{A. Pragmatic Consumption}

First, viewed from the perspective of consumption modes, college students are ready to learn new things and are faster in mastering new technology. Due to issues such as tight learning schedule or economic dependence, students regard in-store purchase as time-consuming or even embarrassing. On the contrary, online consumption can save both time and energy and free people from the limitations of traditional consumption. Nowadays, a series of online payment methods, including WeChat and AliPay, have become increasingly mature. These new payment platforms have proved to be flexible, safe and convenient for college students. Second, in terms of consumption content, college students do shopping online mainly to meet their daily needs, such as food, clothing and accommodation. Of course, they also consume for academic purposes. For example, college students might purchase books and electronic products online. All in all, there are more options and more bargains online and more varieties for college students to choose from.

\section{B. Personalized Consumption}

First, the collision of different cultures under a market economy led college students to pay more attention on the liberation of their personality. Their familiarity with network operations allows them to freely express their opinions and feelings with new cyber-words. Online consumption is a way for them to meet their personalized demands and escape from face-to-face communication. Second, there are different varieties of commodities on the Internet to meet different demands. Some commodities that are too personalized or professional to be found in physical stores can also be found online. College students are eager to be different from others. To purchase these personalized items can distinguish 
themselves from others and meet their demands of being different.

\section{Identity Consumption}

First, commodities are the symbols of identity. For college students, online consumption is fashion as well as a way to realize their values, express their sense of aesthetics, show their personality, and get integrated into a group. Second, college students are mostly in a sensitive and active period. They seek fashion, but are fragile within; they wish to be respected, understood and cared for, yet self-actualization is more important to them. The virtual network is in line with their consumption psychology of seeking novelty, experiences and interactivity. It's fair to say that what online consumption offers is the satisfaction of emotional demands for college students.

\section{COUNTERMEASURES FOR ONLINE CONSUMPTION BEHAVIORS OF COLLEGE STUDENTS}

According to the Survey Report on Chinese Online Buyers, China's online consumption has developed a large group of users, and its development momentum sees no signs of weakening. Besides, online consumption behaviors of college students form an indispensable part of China's online consumption. College students have two identities. First, they are receivers of higher education. Second, they are online buyers. Thus, their consumption behaviors can well reflect their ideas, concepts, values and code of conduct, and can in turn influence the transformation and evolution of network culture and social ideological trends. Joint efforts of the whole society are called for to effectively guide college students' online consumption behaviors. (See below.)

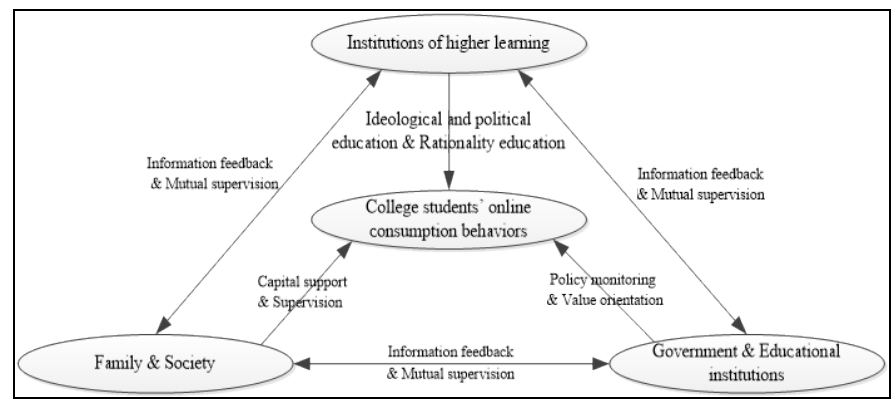

Fig. 1. Three Dimensional Development Mode of College Students' Online Consumption Behaviors

\section{A. Giving full play to the role of institutions of higher learning in ideological and political education as well as in rationality training}

Institutions of higher learning can equip students with advanced knowledge. It is an effective approach to carry forward human civilizations. A favorable campus culture is an organic part of social and cultural environment. It not only reflects students' cultural taste, but also influences their consumption direction. General Secretary Xi Jinping pointed out on the National Ideological and Political Work Conference for Institutions of Higher Learning in 2016 that ideological and political work are closely related to what kind of talents are to be trained, how talents are trained, and for whom are these talents being trained. Moral composition should be at the core of developing talents. Ideological and political work should be included throughout the teaching and education process so as to develop talents in an all-around way. Therefore, institutions of higher learning should give full play to their role in ideological and political education as well as in rationality training. By encouraging civilized and rational online consumption, institutions of higher learning can effectively guide students' material and spiritual pursuits.

\section{1) Develop a Civilized Mode of Consumption}

Virtuality and anonymity of the network creates a perceptual scenario for college students, and can alleviate their anxiety and frustration when they are lost in the cultural collisions. Network symbols, including texts and pictures, allow them to express some social demands which are impossible to meet in real life. Online consumption is not limited by time or space. These novel experiences and virtual interactivity might deprive college students of self-control and they thus become addicted to the network. Meanwhile, in the face of mixed social ideological trends and the explosion of data and information, they gradually lose their ability to analyze and judge. Their intuition might lead them into some negative consumption behaviors, which, in their opinion, are the so-called "fashionable consumption". Besides, online consumption is somewhat recreational and utilitarian, which might easily push college students into hedonism. Thus, it is necessary for institutions of higher learning to give full play to ideological and political education, to bring latest hotspot issues about people's livelihood into classrooms, and to guide students' ability to think and judge by lecturing or group discussions. The advocacy of positive socialist core values can help college students cultivate a positive outlook on life, and guide students to the right track of consumption. At the same time, institutions of higher learning should attach great importance to construction of campus culture. A professional network ideological and political education team should be set up to guide students' value orientation and opinions, create a civilized, inclusive and practical campus and network culture, and keep a close eye on college students' online consumption concepts and trends. All these can contribute to the formation of civilized consumption.

\section{2) Guide Rational Consumption}

College students are active, curious and creative in mind. They are ready to discover and accept novel things, and follow the latest fashion trends. In the face of diversified network information and products, college students cannot control their desire of shopping. However, because of lack of living experiences, their consumption is often impulsive and unplanned. Besides, affected by the market-oriented economy, college students' consumption concepts have gradually shifted from basic demands and emphasis on quality to the taste of the product, service quality as well as brand cognition. Driven by vanity, some college students enjoy showing off their wealth. They blindly purchase famous brands just to compete with others. Therefore, it is imperative for institutions of higher learning to foster rationality in the mind of students. Through rationality training, such as setting up the course of E- 
commerce, students' awareness and ability of financial management can be strengthened. Besides, they will be able to establish a rational consumption concept and develop positive consumption psychology and habit.

\section{B. Giving Full Play to the Policy Regulation and Security Guidance of Government Institutions}

On the 4th Plenary Session of the 18th CPC National Congress, Xi Jinping emphasized on fully promoting the rule of law, and building socialism with Chinese characteristics and a socialist country under the rule of law. Government institutions are national management and service departments. They should fully fulfill their duties in guiding college students' online consumption behaviors. Their role in policy regulation and security guidance cannot be ignored.

\section{1) Standardize Legitimate Consumption}

College students are not yet fully mature. With little social experiences and law knowledge, they cannot effectively screen online information. As a result, they might be involved in online pyramid selling or online frauds. Against this background, government institutions should formulate and perfect relevant policies and plans, and provide authoritative information and services to guide college students to make the right online consumption decisions and standardize the online consumption market as well. Last but not least, government institutions should improve the laws and regulations on online consumption, enhance the publicity of relevant laws and regulations, and use laws to regulate college students' online consumption behaviors. In so doing, we can change external discipline into self-discipline, and create an orderly, healthy and standardized online consumption environment for college students.

\section{2) Strengthen Security of Online Consumption}

As an economic activity, online consumption will inevitably involve issues such as the safety of information, capital and business secrets. In this sense, online consumption is risky. Though college students are well-educated and have different accesses to information, they lack the ability to tell genuine information from false one. Some online payment links might easily mislead them. Their poor awareness of aftersales services and rights protection often turn them into victims of online consumption. Recently, payment code frauds appeared frequently in WeChat payment. Some criminals make use of payers' confusion about payment code and collection code to implement their fraud plans. Victims often do not know how to protect their rights. Concerning cases of the kind, government institutions should intensify their online consumption monitoring, popularize the concept and technique of security and secrecy, standardize online consumption platforms, and create a secure online consumption environment for college students. Moreover, a complete after-sales service system and a complete rights protection system should be put in place. In this way, college students can sharpen their awareness of self-protection and resort to laws to effectively safeguard their legitimate rights and interests.

\section{Giving Full Play to the Role of Family and Society in Capital Support and Decision-Making Supervision}

Family is the place where college students are brought up. Parents' attitude towards life, their habits of living and consumption modes have a subtle influence on students. Thus, family education is critical. College students rely on their family for economic support. While providing fund support, parents should also correctly educate their children. All people are living in a society. None can live alone in separation from the society. As social beings, college students will inevitably be influenced by social values, consumption concepts and the prevailing trends. Therefore, family and society should give full play to their role of capital support and decision-making monitoring so that students can form the habit of healthy consumption and moderate consumption.

\section{1) Encourage Healthy Consumption}

Statistics show that the only child accounts for more than $80 \%$ of college students throughout China. With the improvement of living standards, most families are generous with their children's consumption behaviors. To college students, family is their economic source. Though being increasingly independent, they cannot live without their parents' economic support. Through online consumption, they seek a better material and spiritual life. However, some of them lack self-discipline and are involved in negative consumption culture related to pornography, gambling and drug abuse. Against this backdrop, parents should lead by example by creating a healthy consumption environment for their children. While giving college students capital support, parents should first learn their online consumption demands, and try to guide them into active consumption habits.

\section{2) Advocate Moderate Consumption}

After the opening of the 18th CPC National Congress, the Central Committee of the CPC has advocated the concept of ecological civilization. By putting conservation of resources in the first place, it is committed to building socialist ecological civilization and a beautiful China. Of course, moderate consumption is also included in the agenda. Improvement of consumption awareness in the whole society has a huge impact on college students' moral consumption. A positive social consumption environment can contribute to the forming of positive consumption behaviors. Moderate consumption is not equal to squeezed consumption. Instead, it implies the advocacy of a rational and appropriate consumption mode or a planned consumption habit of living within one's means. Therefore, the concept of moderate consumption should be advocated in the whole society. Besides, the spirit of hard-work and plain living as well traditional virtues should be publicized so as to urge college students to consume based on their practical demands and economic situation, and avoid any waste on online consumption.

\section{Enhancing Information Feedback and Mutual Supervision}

Institutions of higher learning, government institutions, family and society are indispensable for college students to live and learn. These parties should work closely with each other to provide timely information feedback and supervise each other. First, institutions of higher learning should feedback the online 
consumption demands and status of college students to parents and society, and government institutions can guide their online consumption behaviors in a targeted way. Second, after a thorough understanding of college students' online consumption behaviors, government institutions can give feedback to institutions of higher learning and parents so that the latter can guide college students' online consumption behaviors in time. Third, parents and society should take the initiative to contact institutions of learning, learn policies issued by government institutions, guide students to the track of rational consumption, and give feedback to institutions of higher learning and government institutions so that the latter two can formulate the right training plans to improve rationality of college students' online consumption behaviors.

\section{CONCLUSION}

In short, as a large group and the young strength of Chinese online market, college students' consumption behavior is now becoming an important part of daily study and life. The conclusion includes three aspects: firstly, current researches are mainly focus on public consumption behavior while this paper suggests that there are some obvious differences between the college students and the public. We should treat them distinctively. Secondly, this paper investigates from the perspective of ideological and political education, emphasizing on improving consumption concept and ability of college students. Thirdly, college, government, family and society should combine together and cooperate with each other. It is unwise to work individually or rely on others.

\section{REFERENCES}

[1] Marx \& Engels. Selected Works of Marx and Engels[M]. The 4th Volume. Beijing: People' s Publishing House, 1995. (In Chinese)

[2] Feng G. Comprehensive Improvement of the Scientific Level of Party Construction, Ideological and Political Work.

http://news.xinhuanet.com/edu/2012-12/25/c_124141980.htm(In Chinese)

[3] Yao J. P. Consumption Identification[M]. Beijing: Social Sciences Academic Press (China), 2006. (In Chinese)

[4] Decision of the CPC Central Committee on Major Issues Pertaining to Comprehensively Promoting the Rule of Law. http://www.xuefa.com/article-8688-1.html(In Chinese)

[5] Xiang D. J. On the role and task in Internet management of government. [J] Journal of Guangdong Institute of Public Administration 2010.12(In Chinese)

[6] Xu. H. S. An analysis on current situation of on-line consumption of college students. [J] Commercial Times 2009.32(In Chinese) 